\title{
An interview with
}

\section{Adilson Luiz}

\section{Ramos}

» Graduated in Dentistry, School of Dentistry - Bauru / University of São Paulo (USP) (1998).

" Resident in Orthodontics at the Hospital for Rehabilitation of Craniofacial Anomalies/ University of São Paulo (USP) (1989-1992).

" MSc in Orthodontics, College of Dentistry of Bauru/USP (1995).

" PhD in Dentistry (Orthodontics) College of Dentistry of Araraquara / State University of São Paulo (UNESP) (2001).

"Associate Professor at the State University of Maringá (UEM).

" Former Coordinator of the Post-Graduation program in Integrated Dentistry at the State University of Maringá (UEM), from 2008 to 2011.

» Former editor of Dental Press Journal of Orthodontics, from 2003 to 2006.

A long-standing friend. Twenty years ago, we started the Orthodontics program at the State University of Maringá, and I am still surprised by his huge cultural background, his ability to deal with problems and his endless concerns to avoid hurting people's feelings. Our students say that he knows everything from Quantum Physics to Statistics, from Microbiology to Physiology, from Bossa Nova to iPhones and iPads.

He was the editor of Dental Press Journal of Orthodontics between 2003 and 2006, and during this period, the periodical was indexed in SciELO, Scientific Electronic Library Online (FAPESP - Research Support Foundation of the State of São Paulo). We will be eternally thankful for his dedication which was essential to consolidate the periodical in an international scenario. He is a perfectionist orthodontist who has got a huge number of adult patients under multidisciplinary treatment. A researcher who carefully designs his works and advises his students. A professor who is greatly admired by his students and colleagues. A reference for any professor working at our institution. A passionate husband and a father who is absolutely dedicated to his two beautiful daughters. A friend for a lifetime.

How to cite this interview: Ramos AL. Interview. Dental Press J Orthod. 2013 Sept-Oct;18(5):14-31. Submitted: July 10, 2013 - Revised and accepted: August 20, 2013

" Patients displayed in this interview previously approved the use of their facial and intraoral photographs. 
1. As a former editor of the Dental Press Journal of Orthodontics between 2003 and 2006, you were largely responsible for leveraging the high technical and scientific level of this journal, causing it to become one of the most important publications in the Orthodontics field. How do you currently perceive the DPJO and what is your opinion about the scientific quality of the articles published by Brazilian authors, inside and outside the country? (Marcio Almeida)

After you sent your question, we received great news about DPJO being indexed in MEDLINE. It would be quite rude, but I know that this piece of news would be enough to indirectly answer your question. Being indexed in MEDLINE means that DPJO currently fulfills the basic qualifications of an international journal! It is time to celebrate and everyone involved in the DPJO "process", including you as peer-reviewer and author of the journal, as well as readers, news designers, authors, reviewers, editors-in-chief and the entire staff of Dental Press led by Mr. Laurindo and Mrs. Teresa, deserves the glory of this achievement which is unique for the Brazilian orthodontists community. It has been 18 years of an ongoing course. Every editor-in-chief gave one step ahead towards quality standards, culminating in this new achievement. Between 2003 and 2006, we gave our contribution by means of indexing the journal in SciELO - which, at that time, meant national Qualis A, according to CAPES(Coordination for the Improvement of Higher Education Personnel) standards. Such process continued going towards qualification, inevitably influencing the quality of the articles and improving researchers' education. Thus, the process of accurately peer-reviewing well-designed researches has resulted in a "natural selection" in which the limited space available for a great demand caused readers to be reached by the best researches, only. To tell you the truth, this is a quite traumatic, but inevitable process. As in any human-dependable procedure, the process is influenced by different reviewers, which justifies fluctuation in article acceptance - what certainly may be unfair. But, that also happens to the best journals in the world. We know how unpleasant it is to have an article declined. At first, we get "angry" with the reviewers and/or with the editor, and feel they have been unfair to us. However, we end up converting it into an opportunity of growth. We have the chance to mature even more! After all, I am sure that we endeavor to carry out researches which are more focused on design (with new questions and without any gaps leading to negative point of view), since we want to see our works being published in notable journals such as the DPJO and other internationally qualified ones. Thus, after experiencing both sides for many years (as author, reader, reviewer and editor) I can clearly notice a significant increase in quality of Brazilian articles published inside and outside the country.

\section{Taking into account that the smile is one of the} main patterns through which patients evaluate the job performed by the orthodontist, what are the main finishing details that should be carefully looked at by the dentist? (Marcos Janson)

I believe that images mean more than words in this case. I would like to refer to the seven images comprising Figure 1 which are typically considered for frontal smile analysis. ${ }^{16}$ It is important to highlight that, in general, the conditions required for an ideal smile take up slight deviations which can't be noticed by our limited human perception. Answers regarding questions 3, 4 and 5 supplement this answer.

\section{Based on your previously published researches} and your extensive clinical experience of smile esthetics during maxillary incisor retraction, how do you devise a proper plan for space closure in cases treated by means of dental extraction? Which important elements should the orthodontist consider in order to obtain excellent facial esthetics by the end of the treatment?

\section{(Marcio Almeida)}

With regard to esthetic issues in extraction cases, the orthodontist should pay closer attention to the final position of maxillary incisors he intends to achieve after retraction, in which case the three planes of space must be considered. I believe this is the key to attain successful esthetics in any case, and not only in extraction cases. As you have clearly stated, extractions require special care regarding space closure, since that is what will establish labial profile and smile presentation ${ }^{1}$ results. I always remind my students that "profile is affected by retraction, not extraction", in other words, it doesn't matter how space was obtained, the profile changes in accordance with what has been done to the incisors. Thus, in cases with severe lack of space, significant retraction won't be possible; therefore, the profile won't change.

In the anteroposterior plane, anchorage is planned 


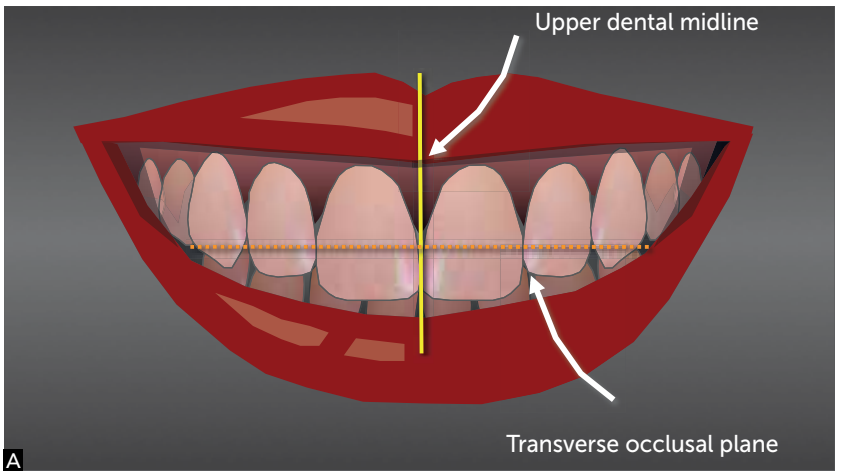

Symmetry and disposition of anterior mesiodistal diameters near the golden proportion

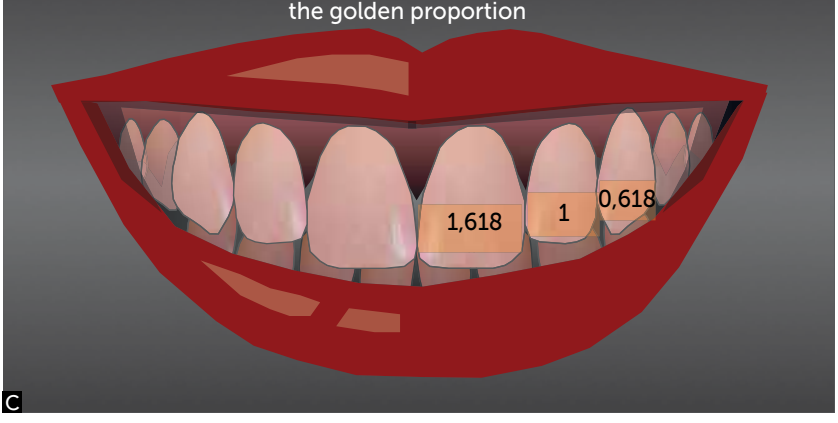

Height: width ratio of central and lateral incisors near 0.8; more extensive proximal contact area between central incisors, progressively smaller in the posterior direction

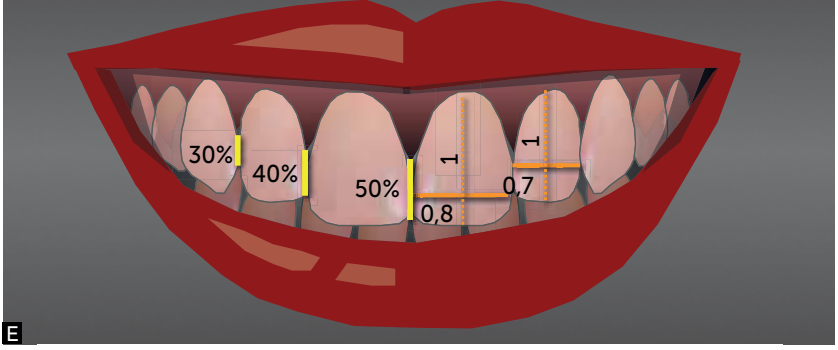

Gingival margin contour

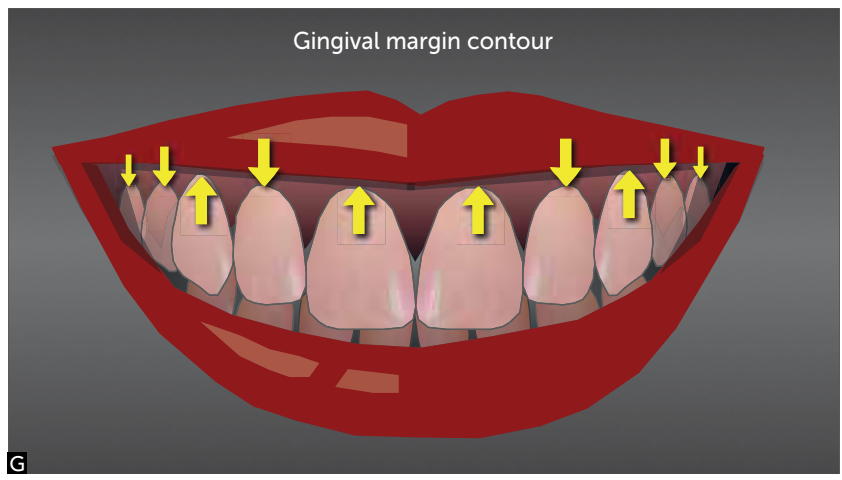

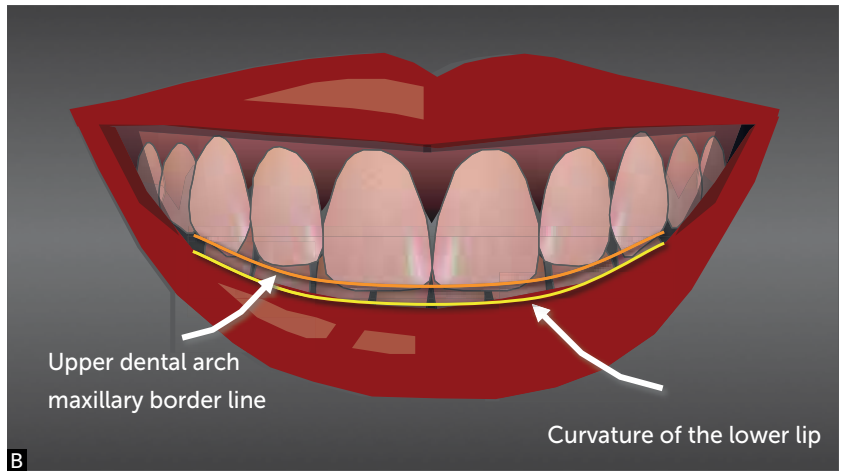
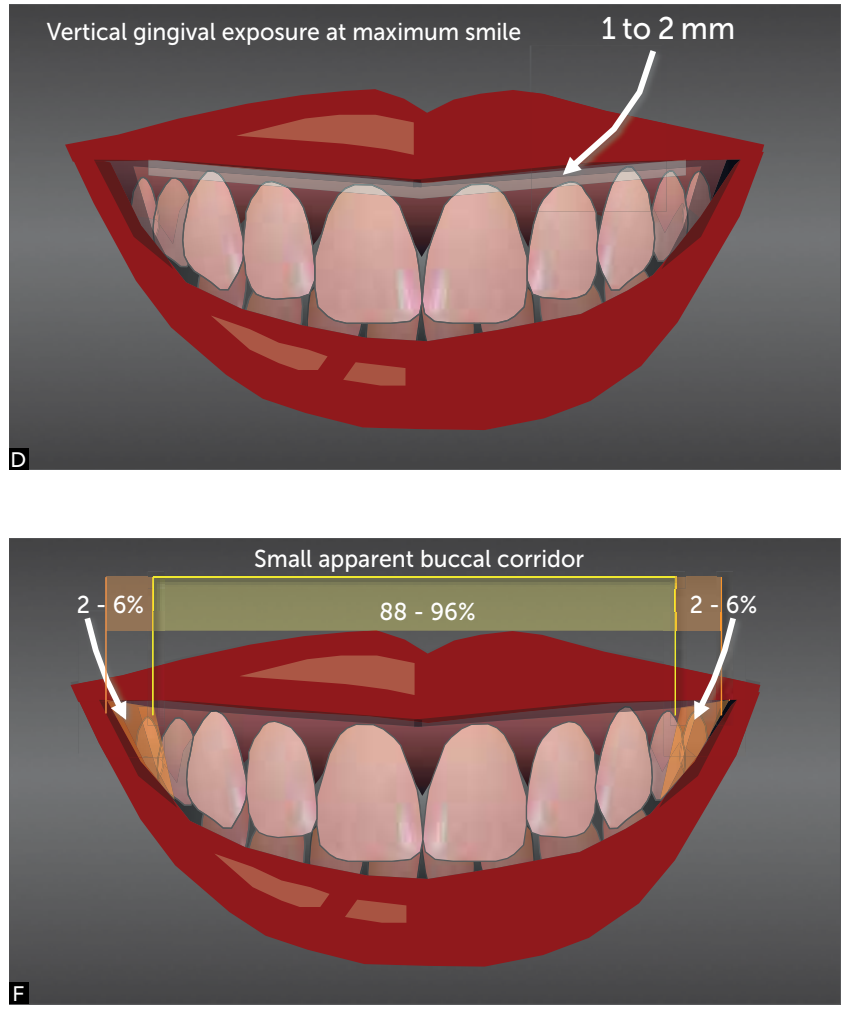

Figure 1 - Classic illustrations showing esthetic parameters for the "ideal smile" that, despite being the ideal situation, can accept slight deviations which can't be noticed by our limited human perception. A) The upper midline must coincide with the facial midline (it is usually equivalent to the middle of the philtrum); and the occlusal plane must be transverse, perpendicular and symmetrical. B) Curvature of the upper maxillary dental arch must nearly coincide with the curvature of the lower lip contour. C) Mesiodistal proportion of central/lateral incisors and cuspids must nearly coincide with the golden proportion. D) Gingival exposure near 1 to $2 \mathrm{~mm}$. E) Extension of proximal contacts, increasing from the incisors to the cuspids, in an average relationship of $50 \%, 40 \%, 30 \%$ in relation to the height of the upper central incisor (the extended contact also contributes to avoid papilla black triangles); Height - width relationship of the central $(0.8)$ and lateral (0.7) incisors. F) From moderate to reduced exposure of lateral buccal corridor. G) Classic gingival margin contour. 
according to the level of crowding, incisor inclination (protrusion) and the need of molar relation correction. The specialization course embraces such concepts which are practiced by means of dental VTO and cephalometric analyses. In short, we understand that the more crowding, protrusion and/or need of Class II correction, the more posterior anchorage we will need in order to retract the incisors. However, with the use of skeletal anchorage (mini-implants or mini-plates), this issue is no longer considered as a relevant technical, collaboration problem. On the other hand, despite being possible, complete retraction of the incisors occupying the spaces created by extraction will not result in satisfactory esthetical profile and smile. I agree with Andrews' statement (given during his speech at the $7^{\text {th }}$ Dental Press International Congress, held in 2012) claiming that the best anteroposterior position of the maxillary incisors is the one which coincides with the vertical Glabellar line (LVV-Gb). In general, that allows the UL3 to be positioned $5 \mathrm{~mm}$ ahead of the true vertical line, resulting in a harmonious upper lip. ${ }^{2}$ With this objective in mind, we need to anticipate the final position of the incisors and the impact they have on the lip. According to one of our researches published in the Angle Orthodontist ${ }^{15}$ in 2005, every millimeter of incisors retraction (when analyzing the cervical point instead of the incisal point, only), will cause the lip to move $0.7 \mathrm{~mm}$ backwards. Therefore, with a $5 \mathrm{~mm}$ incisors retraction, we may expect $3.5 \mathrm{~mm}$ of upper lip retraction. It is worth noting that we are talking about the cervical point (which is more predictable for this correlation) and not about the incisal point (Fig 2) because in incisor retraction, in which inclination is controlled and fulcrum is located close to the apex, a $7 \mathrm{~mm}$ movement in the incisal region may represent $2 \mathrm{~mm}$ in the cervical region, thus, causing the lip to retract $1.4 \mathrm{~mm}(70 \%$ of correspondence to this point). And, in translatory movement, for instance (in cases which incisors do not present buccal inclination and need root torque control), a greater proportional impact is expected on lip profile.

In the vertical plane, it is essential that we establish how much incisor exposure the patient needs when smiling. When incisors are retracted with controlled inclination (fulcrum of apex movement) there will be relative extrusion. In other words, even if the apex doesn't extrude, incisal exposure will increase. In addition to relative extrusion, real extrusion of anterior teeth may occur depending on the mechanics used. Therefore, we must consider the amount of overbite as well as the ex-

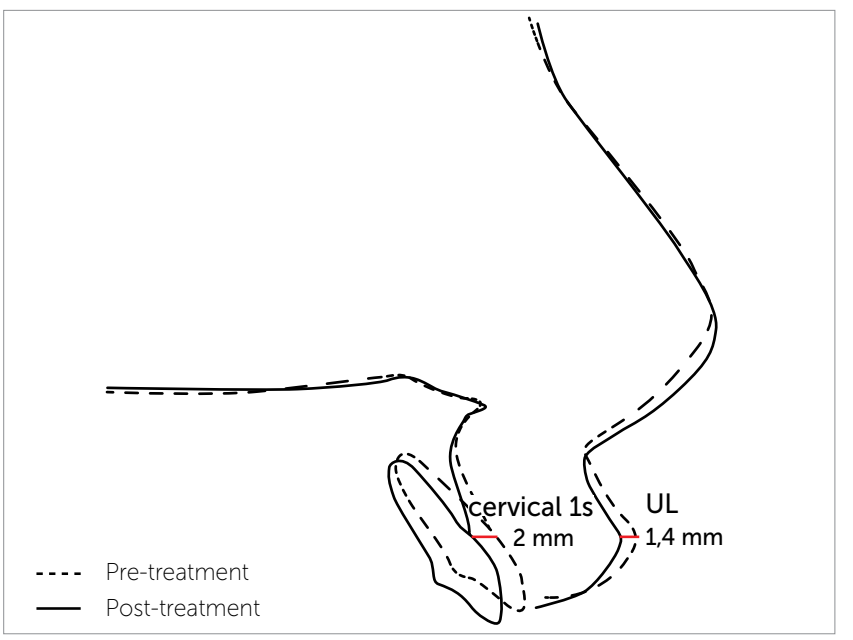

Figure 2 - The impact of upper lip movement caused by retraction of the upper incisors is strongly correlated with the cervical region of the upper incisors and corresponds to a mean retrusion of $1.4 \mathrm{~mm}$ for every $2 \mathrm{~mm}$ of retraction at this point (nearly $70 \%$ of correspondence for this point). The incisal point presents weaker correlation with lip movement. ${ }^{15}$

trusion occurring during the closure phase. In that case, the use of cantilevers or overlay intrusion arches, with or without mini-implants, for example, may be able to control that. ${ }^{1}$ In an esthetically pleasing smile, exposure between 2 and $4 \mathrm{~mm}$ at rest and 10 and $12 \mathrm{~mm}$ on maximum smiling is expected (considering a medium height of $10 \mathrm{~mm}$ for the central incisors, with 0 to $2 \mathrm{~mm}$ of gingival exposure (Fig 1D). ${ }^{16}$ Maxillary incisor exposure is sometimes welcome and necessary to achieve appropriate smile line and exposure (See questions 2, 4 and 5), in which case lower intrusion performed with cantilevers and overlay arches may be necessary to promote upper extrusion.

In the transverse plane, we classically managed the position of the upper midline in relation to the facial midline, the occlusal plane lateral inclination and the transverse arch dimension. Although the aim was to even the midline with the facial midline, many researches have stated that slight deviations (between 2 and $3 \mathrm{~mm}$ ) pass unnoticed and have little influence over smile esthetics. ${ }^{9,12}$ In fact, deviations are tolerated in many aspects of an ideal smile. ${ }^{9,12,21}$ The occlusal plane must be perpendicular to the facial midline (Fig 1A), and this is an unanimous point with regard to esthetics, 
since it is perceived not only by the lay public, but by professionals as well. ${ }^{9,16}$ During retraction (especially if mini-implants have been placed at different heights on each side), we need to pay closer attention to the height of the hooks in order to avoid inclination of the anterior transverse occlusal plane. With regard to transverse arch dimension, especially in four extraction cases, it may have some influence over the appearance of the buccal corridor after space closure. However, torque correction as well as good arch diagram, expansion and coordination are able to circumvent that. It is worth noting that well-performed premolar extractions followed by appropriate mechanics and incisor position control does not have any deleterious effects on smile or profile. On the contrary, if they have been recommended, in general, they are necessary to achieve esthetic objectives.

4. Based on your scientific, professional and teaching experience, which clinical recommendations would you give regarding bracket bonding on upper anterior teeth, with the aim of maximizing smile esthetics?(Daniela Garib)

Strategically and carefully bonding the brackets is essential to achieve satisfactory occlusal results and an esthetic smile. With regard to the smile arch or the smile line, the orthodontist should pay closer attention when placing the brackets in order to favor a symmetric lower lip smile line. Most of the times, this will automatically occur, since in usual cuspid-to-cuspid bonding the brackets are further from the incisal than from the posterior segment. Thus, bracket height (" $x$ ") is greater in the anterior area when using both the center of the crown and placement guide tools " $x$ " as reference (Fig 3). However, this rationale may be disregarded when facing a case of deep overbite, in which case, in the attempt to favor vertical correction, brackets are incisally placed. In this case, upper incisor intrusion (relative or complete) may influence the final esthetic result. In addition to the smile line, occlusal plane inclination plays an essential role in smile appearance. Mesial occlusal plane inclination is usually between $5^{\circ}$ and $8^{\circ}$ in relation to the ground (or perpendicular to LVV). This will allow gingival exposure in the permanent first molar region to be slightly less than gingival exposure in the central incisor region. Should this plane be at $0^{\circ}$, molar exposure tends to be greater than incisor exposure, and should it be at $8^{\circ}$, it tends to be less than inci-

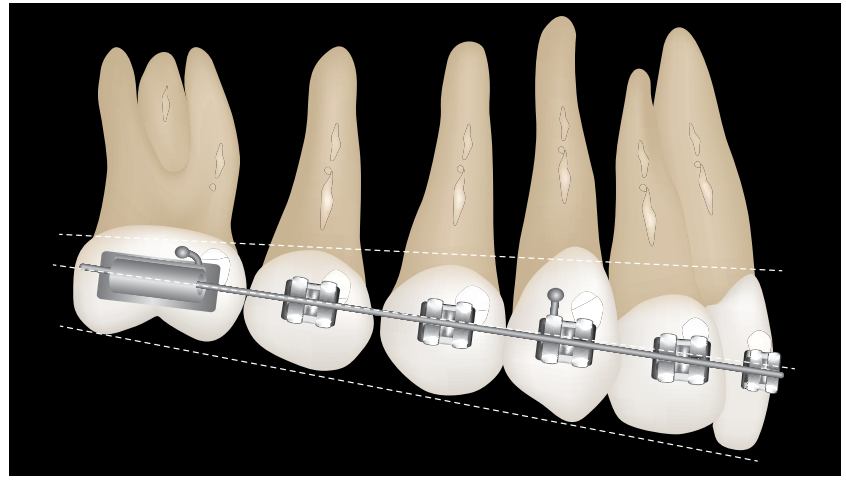

Figure 3 - The bracket bonding height ("x") follows a line that progressively increases from posterior to anterior, which favors a greater exposure of the upper incisors at smile, in addition to correct inclination of the occlusal plane.

sor exposure, which isn't usually esthetic. This variation depends on each patient's facial pattern and lip elevation (commissures versus anterior tubercle) and must be adjusted individually. A smile in which both tubercle and commissures equally raise seems to be more esthetic. Skeletal anchorage and association with orthognathic surgery are usually necessary to achieve these aims.

I would like to take the opportunity to express my respect and gratitude to all your colleagues and professors from the University of São Paulo, School of Dentistry - Bauru (FOB/USP) to whom I owe my graduate, as well as my Masters degree, especially Professors Guilherme Janson, Marcos Roberto de Freitas, Fernando Castanha Henriques, Renato Rodrigues de Almeida, Arnaldo Pizan and Décio Rodrigues Martins (in memoriam).

\section{In one of your editorials published in the Dental} Press Journal of Orthodontics, you pointed out that beauty and self-image appreciation have influenced Orthodontics. You have stood out from the crowd for your studies on the smile and the impact that extractions have on facial profile. Thus, I would like to know which parameters you consider important for facial and smile esthetics which can promote our patients' better self-esteem, and how can we achieve them in our treatments? (Ary dos Santos-Pinto)

With regard to smile esthetics, I have focused on the effects of aging and on potential strategies we can employ to minimize its impacts. Thus, in addition to the basic criteria considered for a harmonious smile, which I have previously mentioned, strategies concerning deep 
overbite correction and mandibular crowding are of particular interest, since these occlusal alterations increase with aging. You have expressly mentioned such points in the Clinical Tip (Dica Clínica) section of the Dental Press Clinical Journal of Orthodontics (Revista Clínica de Ortodontia Dental Press). ${ }^{18,19}$ In brachyfacial or mesofacial patients, usually adults, upper incisor exposure is already small. Therefore, from an esthetic point of view, it is better to intrude the lower incisors or extrude the posterior teeth (or both) in order to achieve vertical correction. This will allow maintenance or increase in upper incisors exposure, which results in a more jovial smile. As for dolichofacial patients, the decision must be determined in accordance with vertical exposure, in which case the upper incisors and/or the lower ones may be intruded, when necessary (however, posterior extrusion is contraindicated). Despite extractions, we must deal with the vertical role the incisors play in the smile as well as in the anteroposterior direction, as previously mentioned in question 1 . Figures 4 to 7 show a case in which deep overbite was corrected by means of lower incisor intrusion associated with extrusion of posterior teeth, aided by a TMA cantilever and an occlusal splint, which allows appropriate incisor exposure and anterior arch curvature to be preserved. Additionally, it has been proven that transverse dimension decreases with aging, which also makes us think about including recovery of posterior tipping in treatment planning, thus, assuring better posterior exposure when smiling. In general, the esthetic conditions shown in Figure 1 must be the aim of any orthodontic treatment in order to minimize the effects of aging.
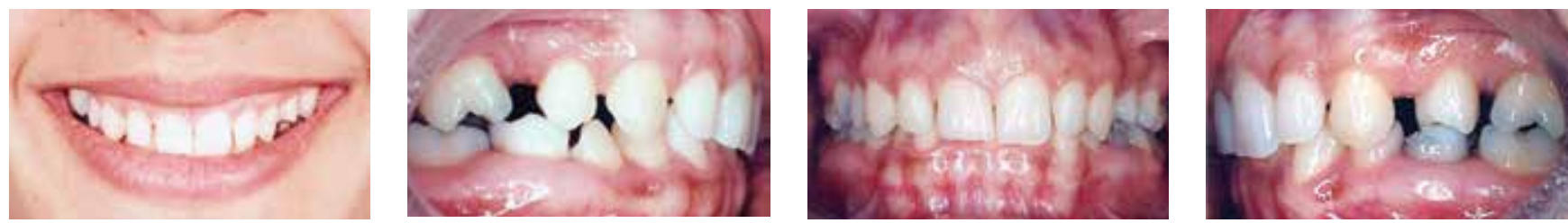

Figure 4 - Initial photographs presenting the anterior region of the smile arc in accordance with the lower lip contour, as well as good vertical exposure. Occlusal aspect demonstrating accentuated overbite in a case with agenesis of four premolars
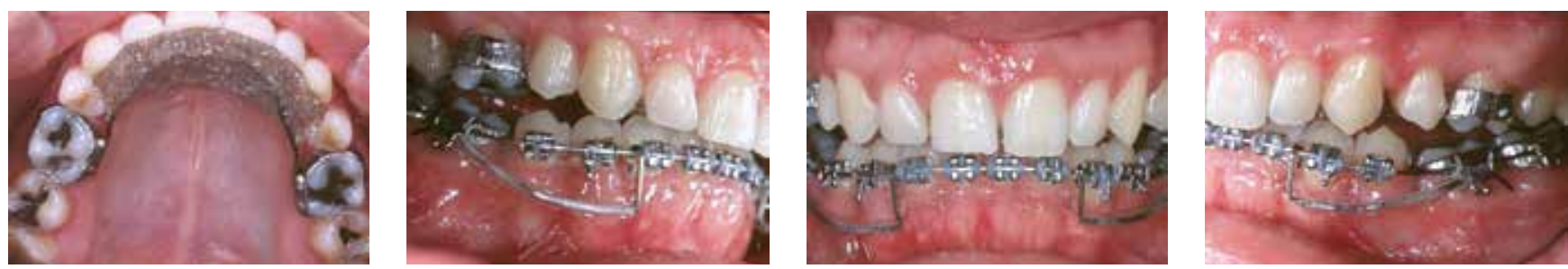

Figure 5 - For overbite correction, an anterior fixed bite plate was used during three months, followed by a removable plate (used at night for 6 months), which facilitated extrusion of the posterior segment and intrusion of the lower anterior teeth performed with two TMA cantilevers combined with a Niti 0.018" x 0.025 " wire.
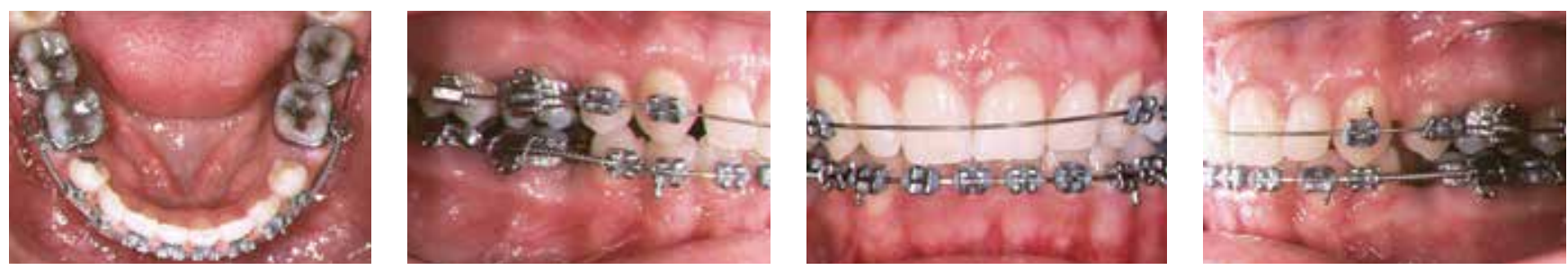

Figure 6 - Partial correction, demonstrating vertical control (anterior superior brackets were avoided at an early stage due to trauma identified at treatment onset, which favored the strategy used for vertical correction, focused on the mandibular incisors and lower posterior extrusion.
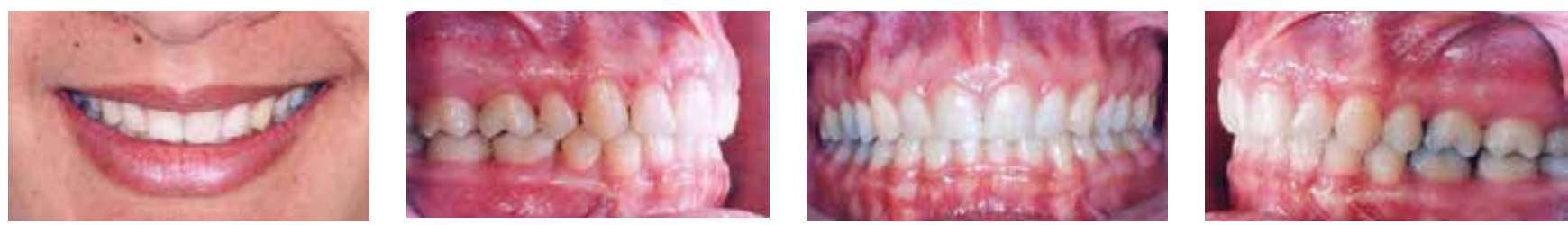

Figure 7 - Smile at the end of treatment demonstrating a preserved contour, exposure of upper anterior teeth and intraoral aspects after orthodontic correction. 
6. On analyzing one of your research lines, we have noticed an increasing interest in using fluoride and fluoride-varnish releasing sealants to inhibit or interrupt demineralization affecting patient's tooth enamel underlying the orthodontic brackets. I would like you to comment on the in vivo clinical effectiveness of such products which you have been studying along with Dr. S. Jay Bowman, one of the greatest names in world Orthodontics. What should we expect from a near future? What are the most recent evidences concerning remineralization of white spots on the enamel after orthodontic treatment?

(Marcio Almeida and Daniela Garib)

I am glad you have mentioned Dr. Jay Bowman's name. I thank him because we started on this line of research after he went to the $1^{\text {st }}$ Dental Press International Congress, held in the city of Maringá, in 2001, during which he instigated us to research about the effects of fluoride varnish. From that point onwards, we developed many in vitro, in situ and in vivo researches with fluoride materials, aiming at lessening the negative effects of demineralization caused during the use of fixed appliances..$^{5-8,13,20}$ Good oral hygiene is still the best way to avoid decalcification, however, due to the fact that many patients have difficulties in keeping it during the whole orthodontic treatment, $50 \%$ of them end up presenting some degree of demineralization.

Most patients may have these minor lesions remineralized after orthodontic treatment has finished; however, cases in which they remain are still very common and may not only evolve into cavity, but also affect esthetics. For this reason, it is reasonable to take some supplementary measures which do not depend on the patient, only. If applied every three months, fluoride-varnish at 5\% (Durafat $^{\circledR}$, Duraflor ${ }^{\circledR}$, among others) has demonstrated a reduction of 40 to $50 \%$ on demineralization, lessening its severity and avoiding its lesion. Fluoride sealants (OpalSeal ${ }^{\circledR}$, UltraSeal ${ }^{\circledR}$ ) have proved to be similarly effective in in vitro studies; however, they may leave some microscopic surfaces or cracks uncovered, allowing demineralization of the enamel to occur. ${ }^{8}$ Furthermore, it is hard to imagine that surfaces such as the proximal areas will be completely covered. Resin sealants do not release fluoride; therefore, they do not present the advantages of the material they are made of (glass ionomer cement, varnish, solutions, gel). However, reduction in viscosity of new products, such as the ICON ${ }^{\circledR}$ which is considered as infiltrating, allows treatment of white spots and results in relative color stability. ${ }^{11}$ Furthermore, still regarding preventive issues, some researches have also demonstrated reduction of 40 to $50 \%$ with products containing CPP-ACP (casein phosphopeptide - amorphous calcium phosphate). I have recently tutored a Masters degree student whose thesis shows promising preventive and remineralizing effects, except for the in situ study carried out with Dessensibilize Nano- $\mathrm{P}^{\circledast}$ (FGM). It is a compound made of nanometric calcium phosphate (in the form of hydroxyapatite), sodium fluoride (9000 $\mathrm{ppm}$ ) and potassium nitrate. It is recommended to be applied once a week in the first month, with monthly reapplications, if necessary. In addition to these materials, resin glass ionomer cement, used for bonding brackets (FujiOrtho ${ }^{\circledR}$ and similar ones), may reduce prevalence of white spots from 40 to $50 \%{ }^{14}$. However, the great incidence of bracket falling off when resin glass ionomer cement is used may be considered as an operational problem. In a near future, I believe that these materials will be improved (both the adhesives and the regular-application ones) so that they can be used especially for higher risk cases, thus, eliminating the side effects caused by orthodontic treatment.

7. What do you suggest younger patients do, especially those with poor oral hygiene, in order to prevent decalcification of enamel during orthodontic treatment? And what would be the most appropriate treatment after calcification has already occurred? (Marcos Janson)

Usually, orthodontic patients receive instructions on oral hygiene before bracket bonding, besides being motivated at every section. However, although they know that the best thing to do is to have good oral hygiene, we observe that patients have difficulty in systematically keeping it during orthodontic treatment. Therefore, in the most serious cases, I apply fluoride-varnish (Duraphat ${ }^{\circledR}$ ) every three months, which is considered a simple method. The procedure includes prophylaxis (only the gross plaque needs to be removed), relative isolation (with oral retractor), drying and varnish applied with a microbrush, especially in gingival and proximal surfaces. Afterwards, the retractor is removed and the varnish layer is left to coagulate by saliva, which turns out to be light-yellow (Fig 8). Patients are advised not to brush their teeth within the next 12 hours.

In addition to varnish, I occasionally use glass ionomer cement reinforced by resin (Fuji Ortho ${ }^{\circledR}$ LC) for bracket 
bonding in cases presenting white spots before orthodontic treatment onset. In addition, glass ionomer cement is used to cement the bands. It has the potentiality of protecting the proximal surfaces to where it is applied. ${ }^{14}$ Despite all the care, white spots may occur. Therefore, some clinical measures may be taken in order to treat or minimize the effect of those lesions, as follows:

1) Monitor the lesions by means of implementing prophylaxis and monitoring oral hygiene, supplementing it with low concentration fluoride $(0.05 \%)$ applied on a daily basis. Occasionally, associate it with dental bleaching procedures in order to mask fluorosis.

2) Remineralizing agents, such as the CPP-ACP $\left(\right.$ Mi-Paste ${ }^{\circledR}$ ) and Desensibilize ${ }^{\circledR}$ Nano-P, applied once a week during the first month and once a month afterwards.

3) Microabrasion (pumice + phosphoric acid at 37\%, $20 \mathrm{sec}$ ) followed by fluoride gel at 1\% (1 min).

4) Infiltrant resins $\left(\mathrm{ICON}^{\circledR}\right)$ and resin fluoride sealants (Pro-Seal ${ }^{\circledR}$, Ultraseal ${ }^{\circledR}$ ).

The sequence presented above may vary according to lesion severity and esthetic effect. Thus, in less severe cases, the procedure must be more conservative, as in options 1 and 2. Should these options fail, 3 and 4 must be carried out. Recently, low-viscosity infiltrant resins have proved to be clinically effective to treat such lesions, with an optic effect that is similar to a healthy enamel. ${ }^{11}$

\section{Do you believe that there has been a decrease in demineralization of enamel during orthodon-} tic treatment in association with an increase in the number of patients with fluorosis and who are cavity-free? What would you recommend regarding the application of fluoride varnish in cases of demineralization of enamel around the orthodontic bracket, one of the themes of your line of research? (Ary dos Santos-Pinto)

Although the most recent researches have pointed out that demineralization of enamel is frequent during orthodontic treatment, in fact, we have noticed that it has decreased in the last 10 or 15 years of our clinical practice. Frequent use of glass ionomer cement for banding, motivation for brushing (with fluoride toothpastes) and supplementation with topical fluoride may explain the decrease in white spots lesions. However, this issue is still a problem! There are still patients who do not cooperate with hygiene.
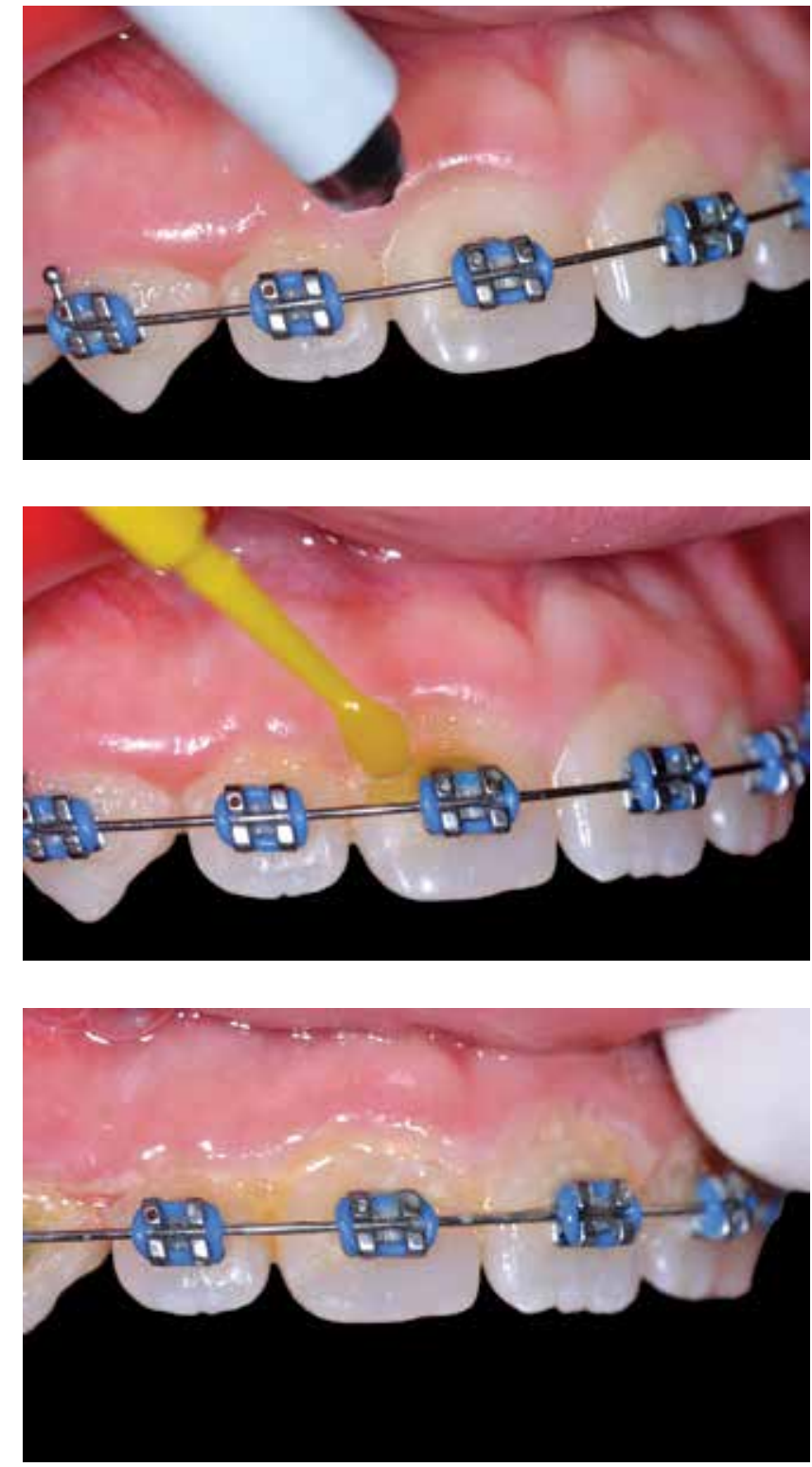

Figure 8 - Topical fluoride varnish application must be carried out every three months and consists of a simple procedure involving biofilm removal (prophy laxis), drying, varnish application and coagulation by saliva. The final aspect is light yellow. Tooth brushing should be avoided within the first 12 hours.

As you have highlighted, some younger patients come to us cavity-free, but with associated fluorosis or not with enamel hypoplasia. Patients presenting different characteristics intrinsic to the enamel may also suffer from superficial or subsuperficial demineralization during treatment, due to difficulty in removing dental plaque, as we have already discussed in questions 6 and 7 in which we mentioned the varnish application protocol. Figure 9 shows an ordinary case of a patient with hypoplastic spots and subsuperficial lesions worsened after orthodontic treatment. 
9. Could you comment on the effects the segmented arch technique had on your education as an orthodontist, when you went for the PhD degree at State University of São Paulo (UNESP) in Araraquara? Which aspects of the technique have you frequently used in your clinical activity and what do you consider to be important when teaching this treatment philosophy?

(Ary dos Santos-Pinto)

Being exposed to the concepts of the segmented arch technique was, undoubtedly, a privilege for my education. Orthodontic mechanics is no longer mysterious once the segmented arch concept has been understood. Although conventional cases have been mainly treated with the Straight-Wire technique, I apply the segmented arch for molar uprighting (Figs 10 to 13), anterior intrusion, root correction loop, cantilevers to pull unerupted teeth and geometries for the palatal bar and the lingual arch. These techniques greatly facilitate the evolution of treatment, avoiding undesired side effects on adjacent teeth. Understanding the segmented arch mechanics also enables us to clearly see the effects of forces applied in cases of skeletal anchorage. I am certain that segmented arch concepts must be included in orthodontic education. I would like to publicly thank you and other illustrious professors who were part of my education during the $\mathrm{PhD}$ course taken in Araraquara: Tatsuko Sakima, Maurício Sakima, Dirceu Raveli, Luiz Gandini, João Gonçalves, Joel Martins (in memoriam).

10. During your orthodontic education, as a trainee, you performed treatment in cleft lip and palate patients with craniofacial anomalies. How did this experience influence the procedures and conducts you have employed during your professional life in patients with no anomalies?

\section{(Daniela Garib)}

I worked at the Hospital for Rehabilitation of Craniofacial Anomalies/USP between 1989 and 1992. Hundreds of words would be necessary to express how much it influenced my education. Let me mention a few. In the orthodontic field, I had the pleasure to count with Professors Omar Gabriel da Silva Filho, Leopoldino Capelloza Filho, Reinaldo Mazzotini, Terumi Okada and other colleagues from the Orthodontics Sector, as my first and greatest professors. What I learned there went beyond my orthodontic practice with cleft patients and/ or those with anomalies. I also have to mention the opportunity I had to be in touch with Dr. Luiz Alberto de Souza Freitas (Uncle Gastão) who I also would like to thank for his advice, leadership and friendship. I can say that not only the professional experience I acquired there, but also the human conduct I was exposed to have strongly influenced my education. At the Hospital for Rehabilitation of Craniofacial Anomalies/USP, I witnessed a unique dedication of those who were involved with patients (experts, technicians and staff members of different areas and levels). And this is essential to have a successful clinic or institution. Professional integration and team work are key to success as well. At that hospital, I began to understand how necessary that was and started to develop real interdisciplinary plans. Perhaps, one of the greatest lessons I have learnt was about respecting patients' ambitions (their chief complaint) and limitations. Even though we intend to make changes and corrections in order to achieve perfection, we have to admit that Genetics is often implacable in limiting our interventions. And the latter are routinely practiced in any clinic!
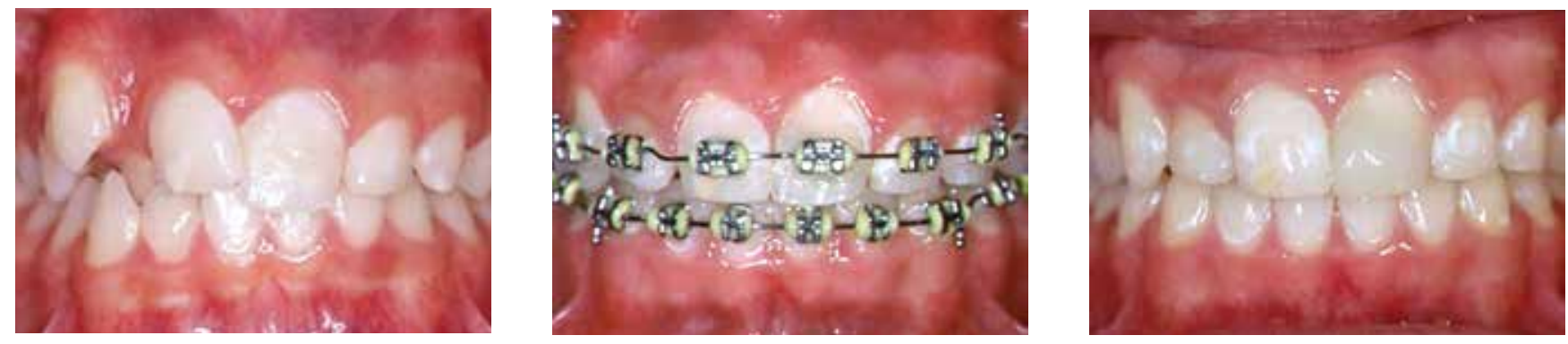

Figure 9 - Trans and post-treatment initial aspect of a patient with enamel hypoplastic spots and white spots worsened after orthodontic treatment. 

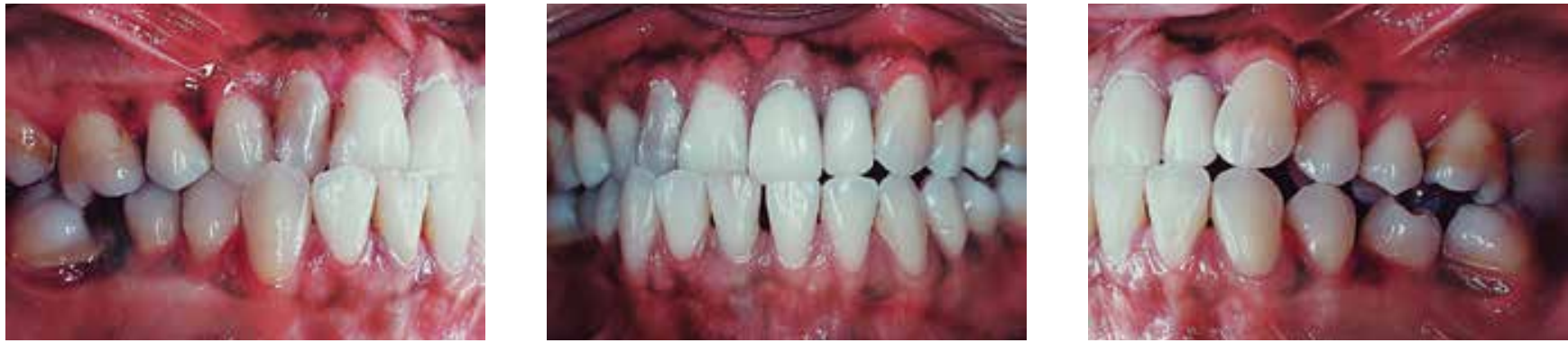

Figure 10 - Class III malocclusion, with loss of mandibular first molars and accentuated mesial angulation of second molars towards the space, in addition to absence of \#12 and root damage of \#22.
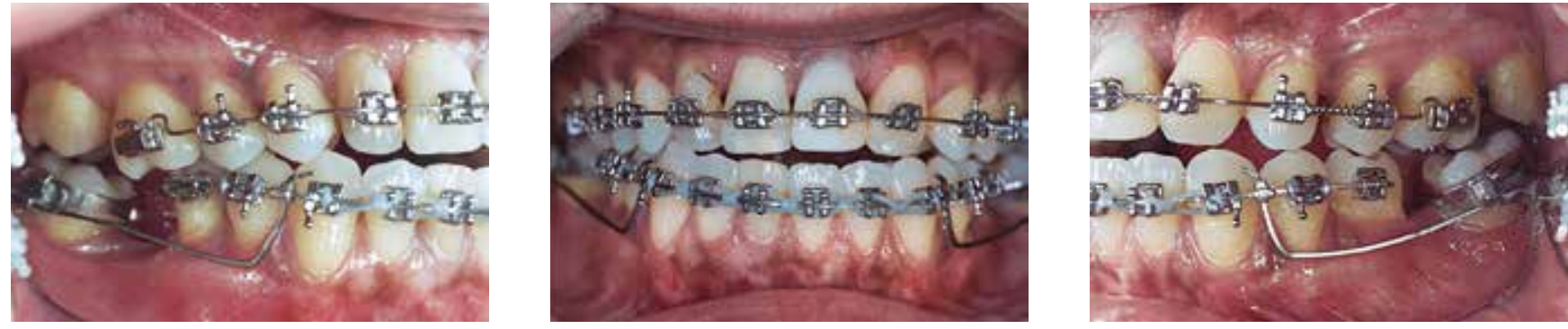

Figure 11 - The use of a statistically undetermined system, with a TMA wire connected to the cross tube in the anterior region, allowed controlled second molars uprighting, which resulted in movement of the anterior block favoring the use of Class II elastics associated with mechanics of upper posterior segment mesialization.
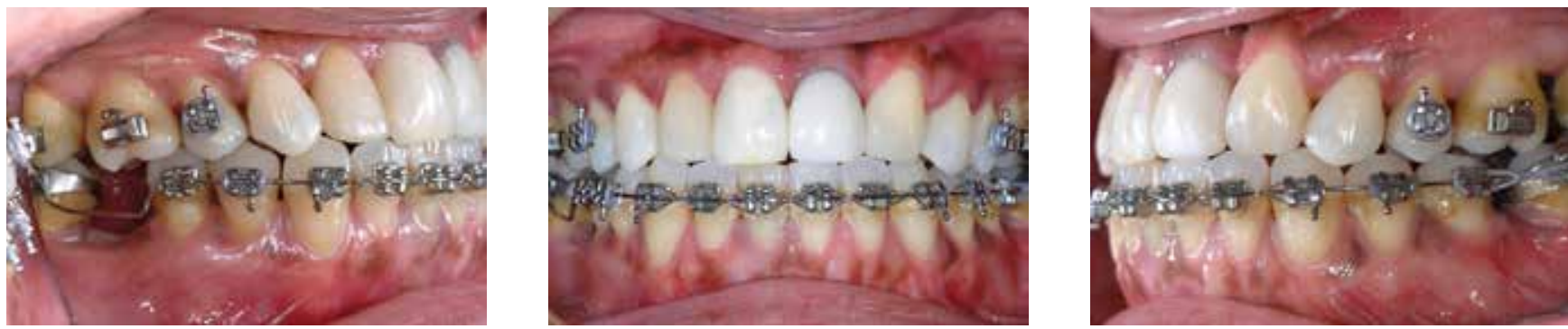

Figure 12 - Occlusal aspect after molar uprighting. Implant space, prosthesis in the \#46 ("third pre-molar") and space closure in the \#36 region were kept. The upper fixed appliance was partially removed in order to allow restoration/reshaping of upper anterior teeth. The canines were placed in the position of the upper lateral incisors. Orthodontic treatment was immediately resumed.
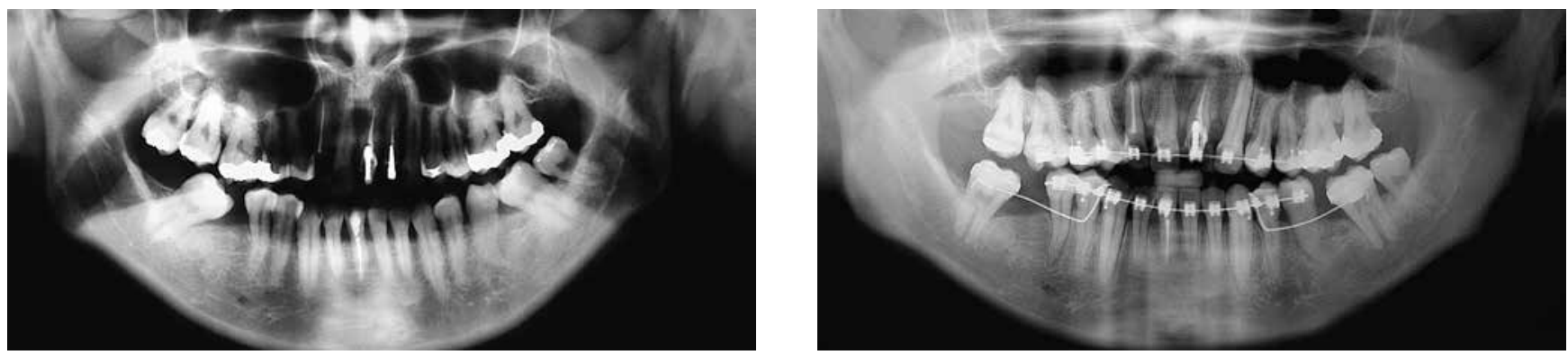

Figure 13 - Panoramic images taken before and after molar uprighting carried out by means of segmented mechanics. 
11. Many adults have sought orthodontic treatment, especially in Implantology and Orthodontics. For this reason, these patients' bone condition has become a relevant aspect for treatment planning and therapy. I know you have developed some researches in this area. Therefore, I would like to know more information about this subject and how we can apply them in our daily practice. (Ary dos Santos-Pinto)

As orthodontists, we have actively participated in rehabilitation plannings which must be carried out in an integrated manner before any specialty begins their own intervention. Thus, my colleagues from the Prosthesis, Periodontology, Cosmetic Dentistry, Surgery and Implantology fields and I have helped with the decision making process concerning the attachment of prosthetic components (over implants or not), extractions, ridge points that can be improved, space distribution and possibilities of vertically handling occlusions, among others. Many issues regarding rehabilitation have become a thing of the past, for instance, angulated abutments which used to be solved by means of abrasion on dental structures or making angulated nuclei. Uprighting as well as obtaining better spaces can be easily performed by Orthodontics. Increasing the vertical dimension of occlusion as well as intrusion of posterior and anterior teeth are some other possibilities that allow new prosthetic-restoration plannings. These possibilities have been improved with skeletal anchorage and allow more accurate predictability. I also would like to highlight both vertical and horizontal tooth movements performed to recover the alveolar bone, which facilitate our job. ${ }^{10}$ The vertical movements, which have been performed for a long time, are, for example, root extrusion to recover biological distances and extrusion, which may be followed by extraction for leveling the alveolar ridge. Movements performed on the edentulous ridge, however, are no longer considered as a model, although further studies prove to be necessary to understand the maintenance after insertion of retracted teeth or predictability of alveolar dimensions caused by movement. We have recently advised some researchers who developed a study showing that there is an average loss of $1.5 \mathrm{~mm}$ in the adjacent crest due to movement. However, the overall bone gain is clinically relevant not only in the buccolingual direction, but also in the alveolar height, thus being superior to such little crest loss. ${ }^{17}$ Thus, the contribution given by Orthodontics has been decisive to reduce the need of grafts (or its area) and, more advantageously, the predictability of the ridge height where the implant will be placed. Figures 14 to 28 show some of these situations.

\section{Based on the development of the Digital Age} in Orthodontics (3D analysis, dental casts, CBCT), the paradigm shift in orthodontic diagnosis with emphasis on the face, reappearance of lingual Orthodontics and self-bonding brackets, skeletal anchorage, removable aligners as well as surgical and non-surgical resources for speeding up tooth movement, what do you expect for Orthodontics in the next few years? (Marcio Almeida)

I believe we can say that this is a self-answering question. The great innovations you mention have taken the orthodontic practice to a higher degree of predictability and esthetics, which has been more and more accepted by our patients. The increasing demand of adult patients for orthodontic treatment stimulates innovations in many respects and integration among areas enables the achievement of satisfactory results. I believe that among the trends you have mentioned, the non-surgical resources performed to speed up tooth movement (the use of local medication, for example) and a more comfortable and practical appliance design may cause treatment to be even more accepted by patients in the next few years. If we think how popular the use of mini-implants has become to facilitate mechanics, and if we ponder patients' high acceptability with regard to Botox injection for transitory esthetical effects (used in Dermatology and cosmetic procedures) we can see that local mediators injected in areas of tooth movement may become feasible options to speed up or hinder movement, in addition to contribute to tissue regeneration in damaged areas, increasingly interacting with other specialties. So many innovations, which will always occur, have consolidated the idea that in addition to excellent specialty education, we need to count on a continuos update regarding the new technologies, thus offering even better options to our patients. This makes orthodontic practice even more exciting! 

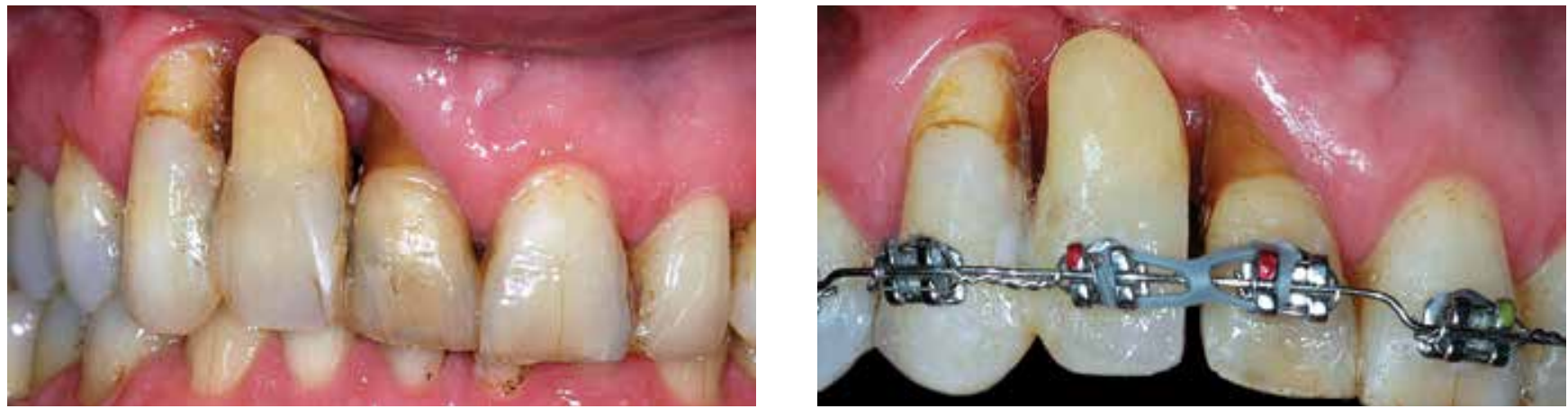

Figure 14 - Initial photographs of a case with accentuated bone loss in the \#12, with a history of three unsuccessful graft attempts. Smoking and lesion extension may have contributed to such lack of success.
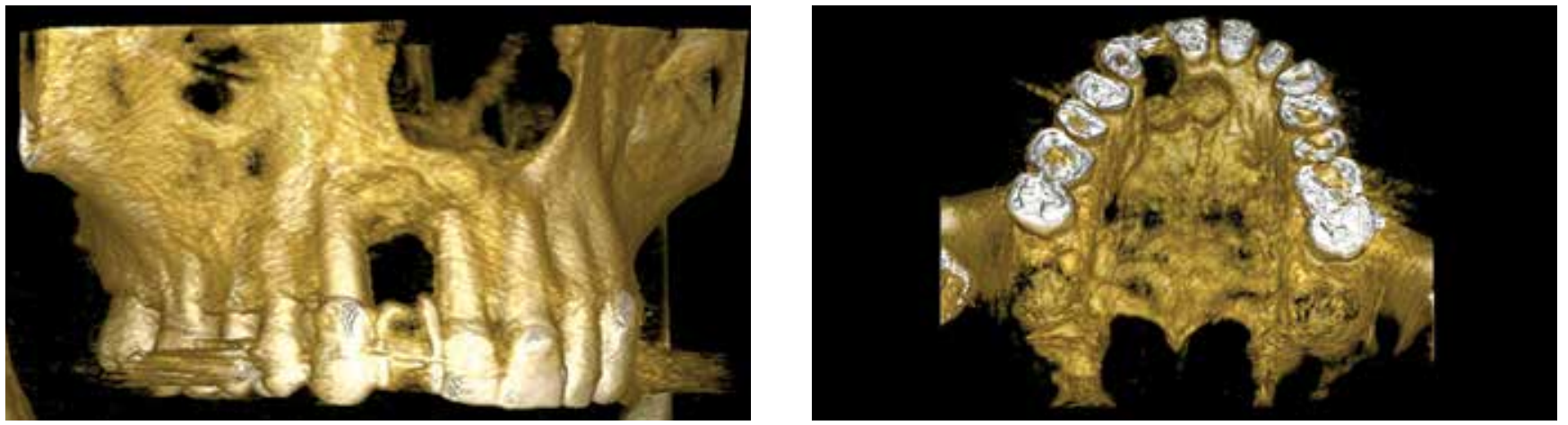

Figure 15 - Tomographic reconstructions of areas with bone loss.
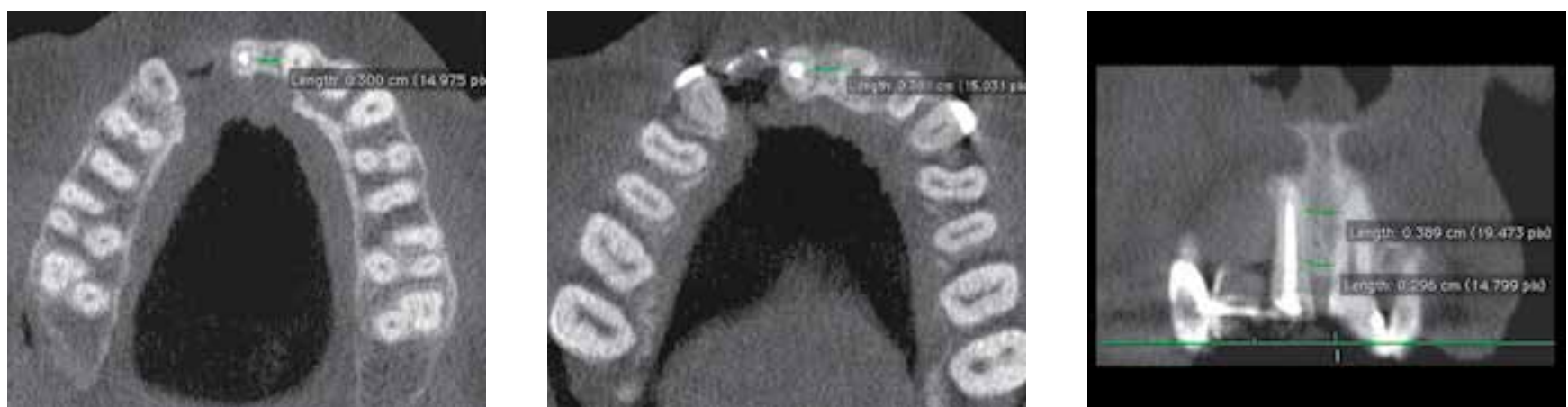

Figure 16 - Tomographic slices of the inter-radicular distance between central incisors, taken before treatment. Nearly complete absence of bone tissue mesially to \#11, however, with its structure distally preserved.
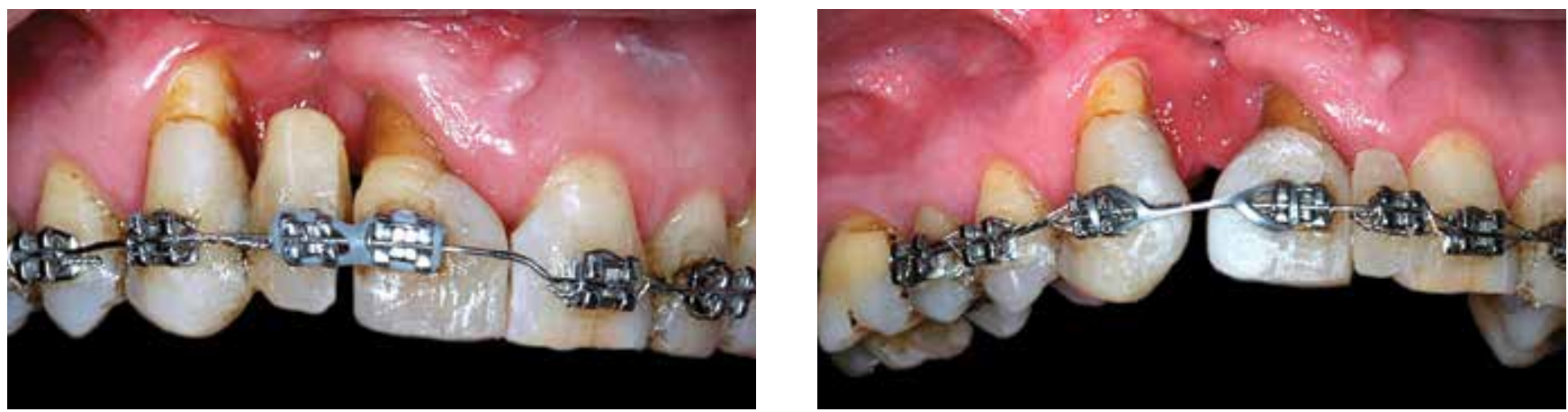

Figure 17 - Beginning of \#11 movement towards the affected site. 

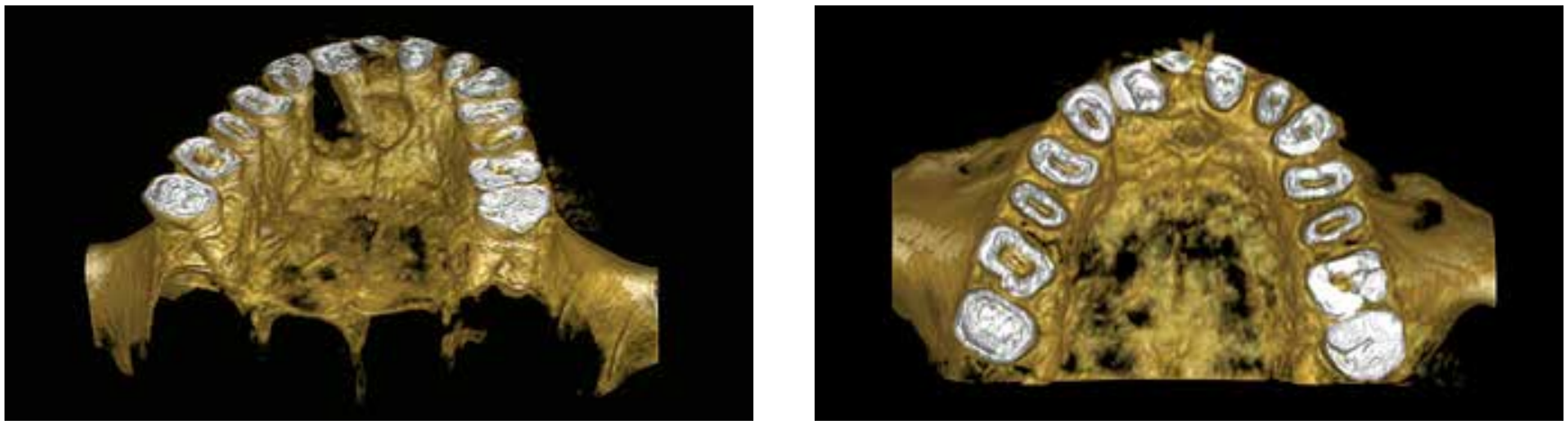

Figure 18 - Tomographic reconstructions after \#11 was distalized in place of \#12. Despite crown angulation, significant bone gain was observed, preparing the site for implant placement in the \#11.
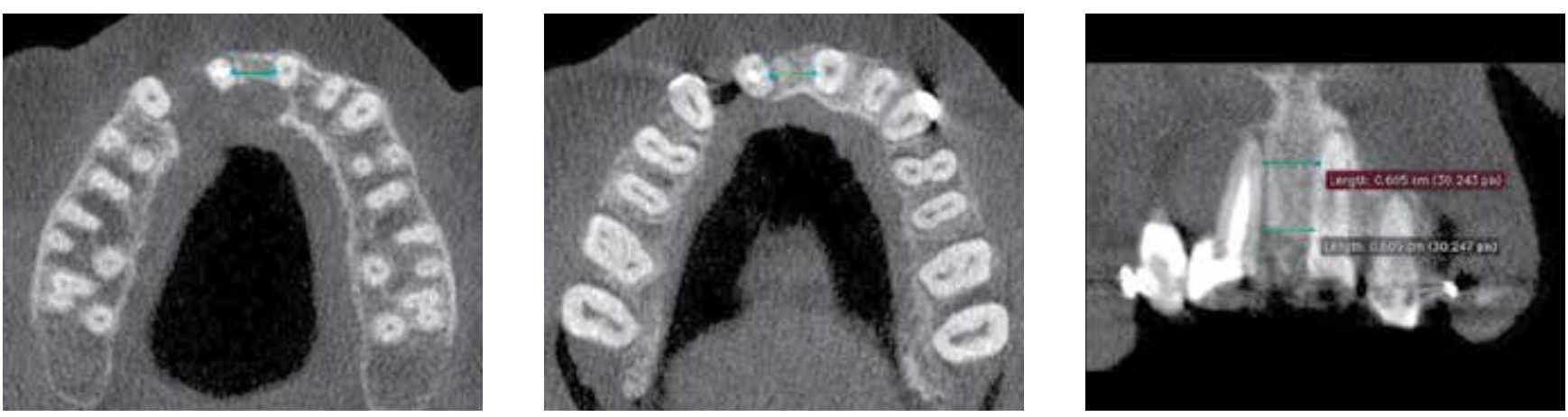

Figure 19 - Tomographic slices demonstrating appropriate space (both vertical and horizontal) for implant placement, taken after treatment.
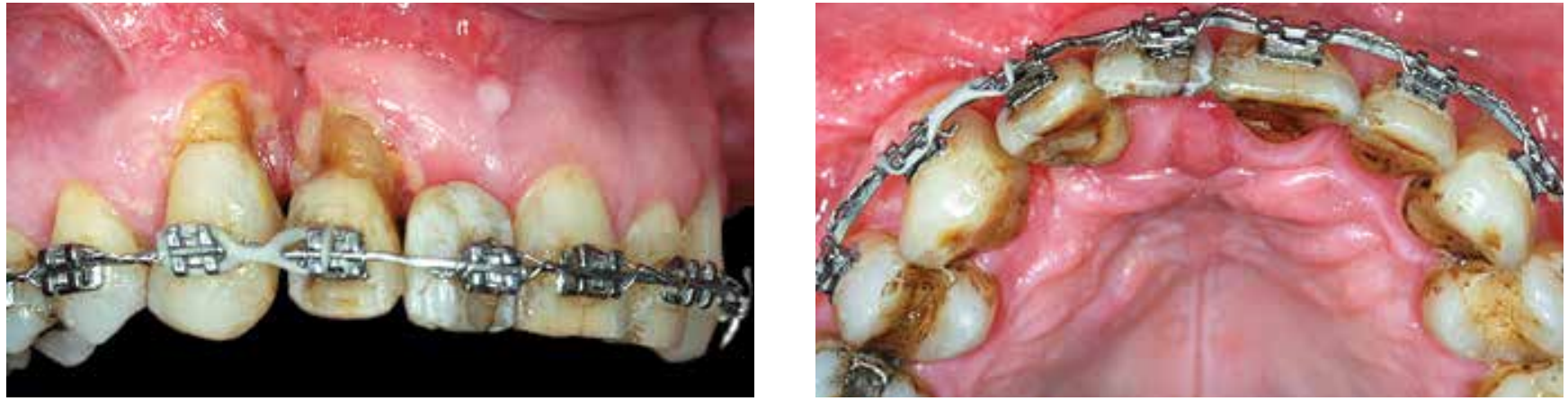

Figure 20 - Clinical aspects of the affected area demonstrating improvements in the area with bone loss, in addition to alveolar displacement for the \#11.
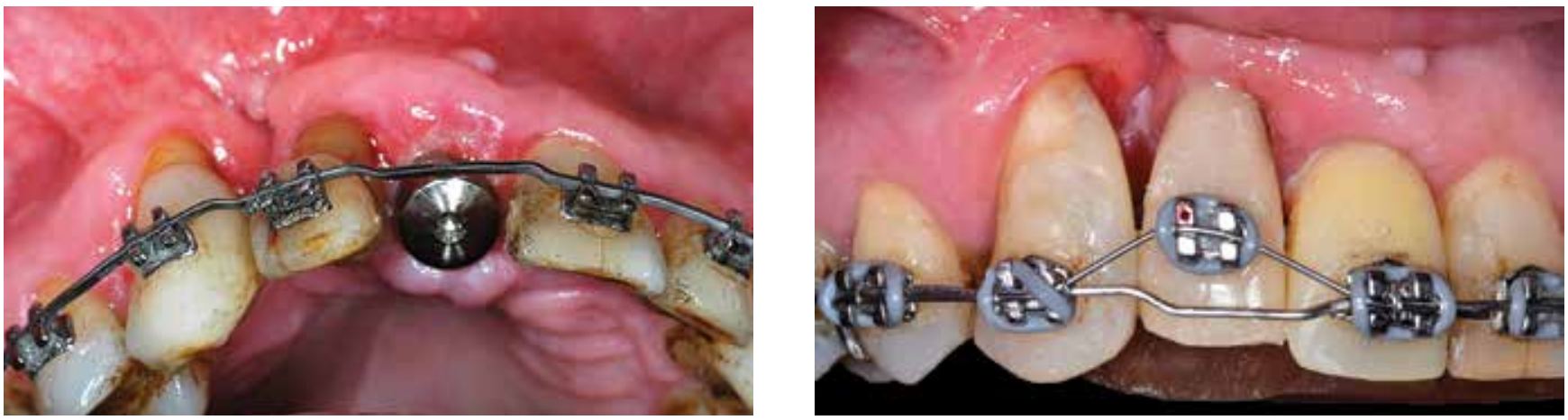

Figure 21 - Implant placement in the \#11 region. After new restorations and provisory placement over the central incisor were performed, \#12 was extruded a little more in order to obtain vertical bone gain and partial improvement in gingival margin. 

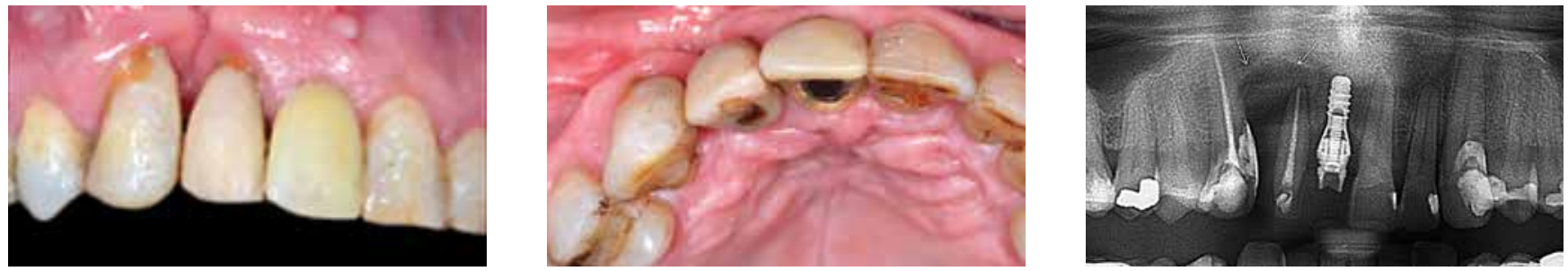

Figure 22 - Photographs taken after the orthodontic appliance had been removed, when the patient was referred to periodontal reevaluation and feasibility of bone graft in the bone loss area. The affected site is evident, as can be seen in the radiographs, despite the significant reduction resulting from the treatment and the feasibility of implant placement in \#11.
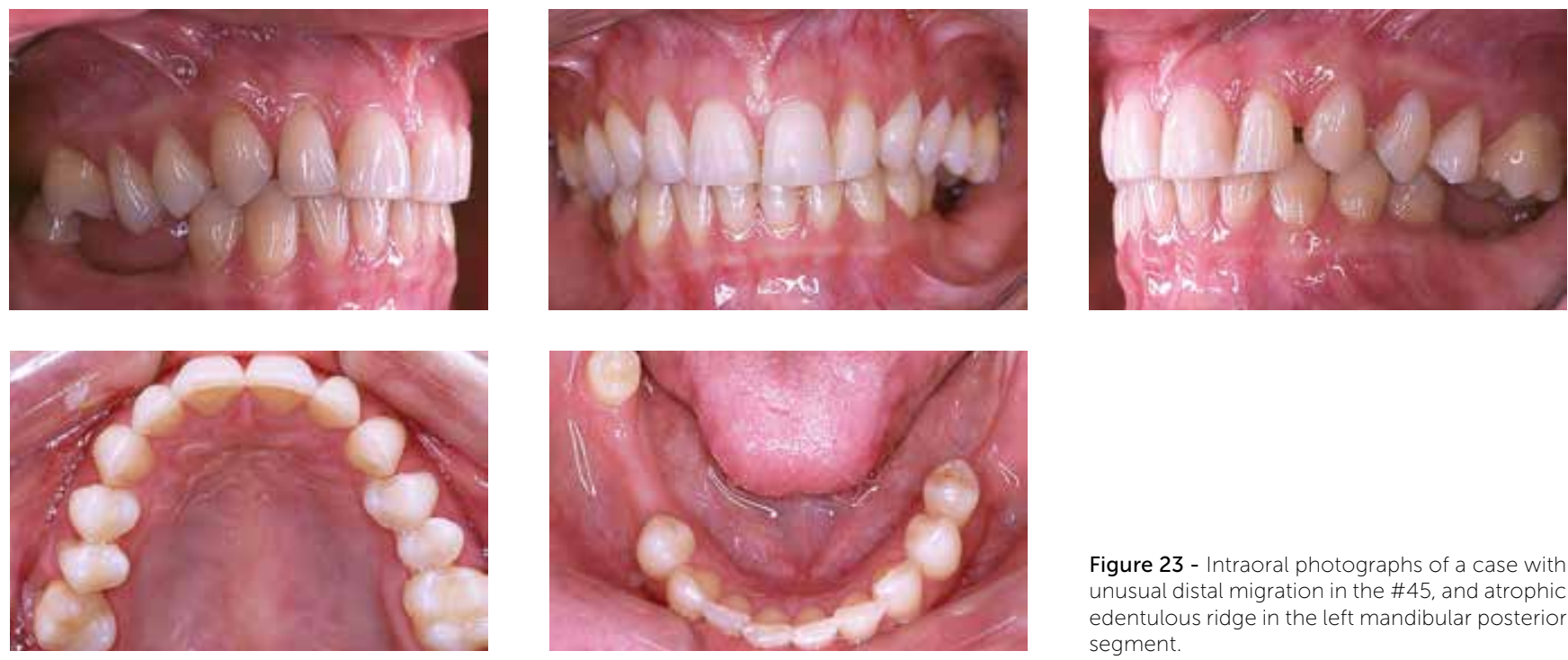

Figure 23 - Intraoral photographs of a case with unusual distal migration in the \#45, and atrophic edentulous ridge in the left mandibular posterior segment.
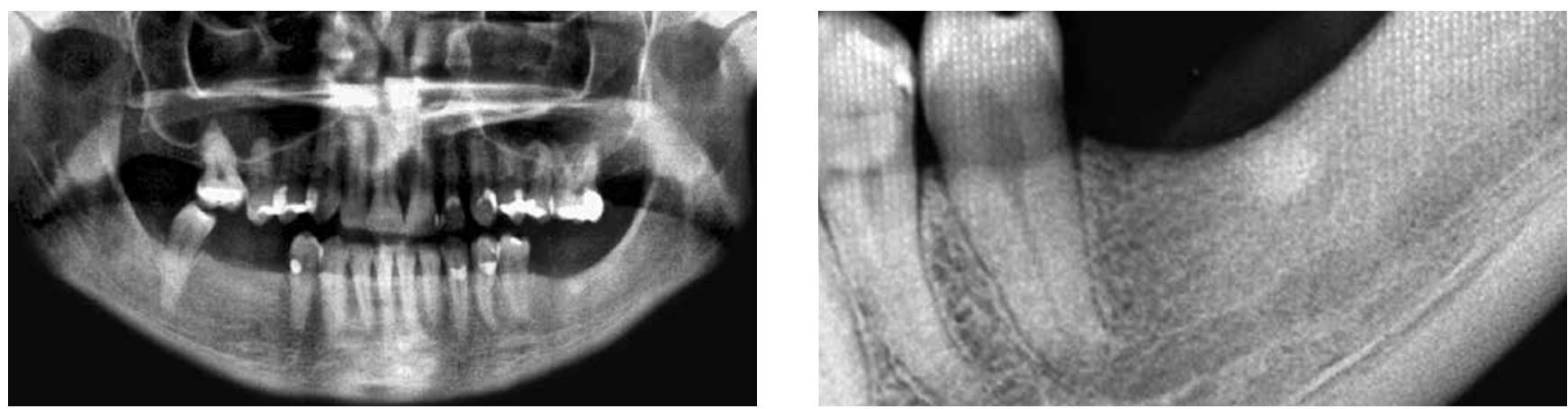

Figure 24 - Panoramic and periapical radiographs of the \#36 demonstrate alveolar vertical reduction. 

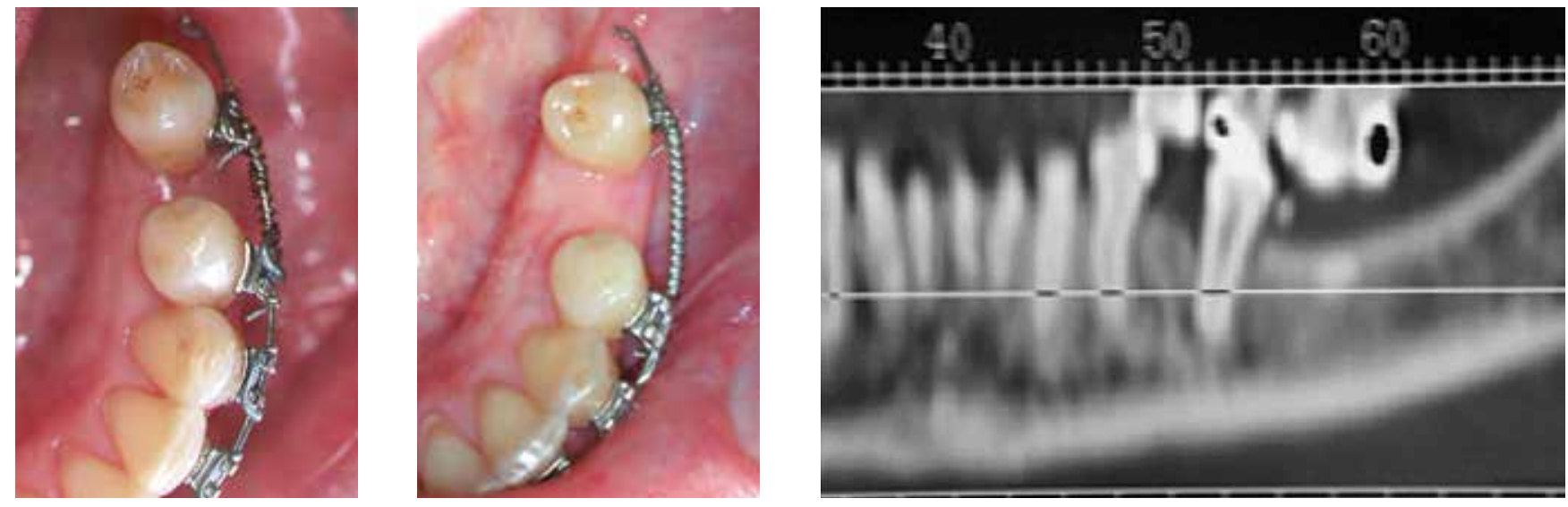

Figure 25 - Orthodontic treatment aimed at distalizing \#35 in order to promote alveolar recovery prior to prosthesis placement over the implant. The tomographic slice taken after distalization demonstrated bone quality good enough for rehabilitation.
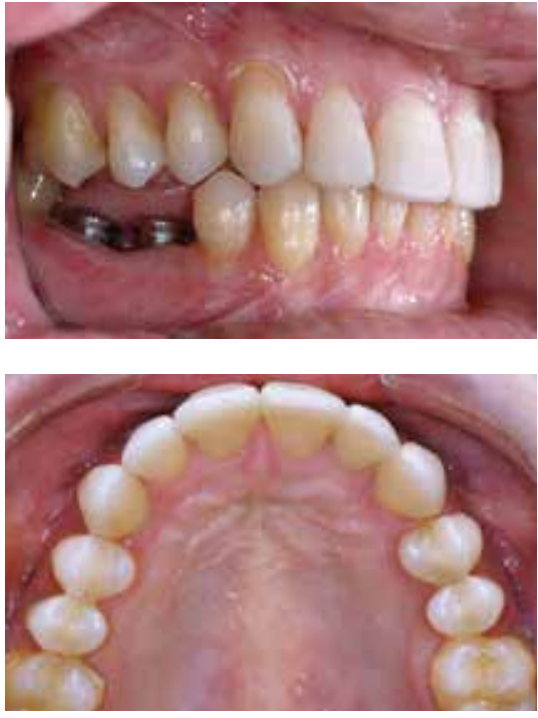
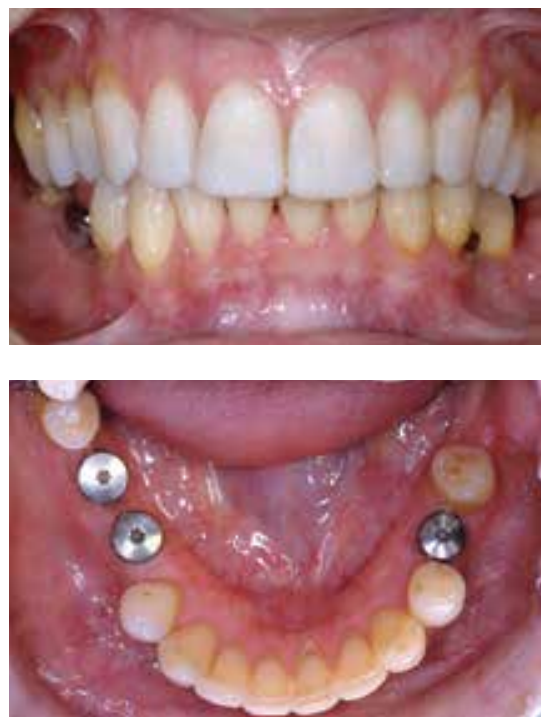

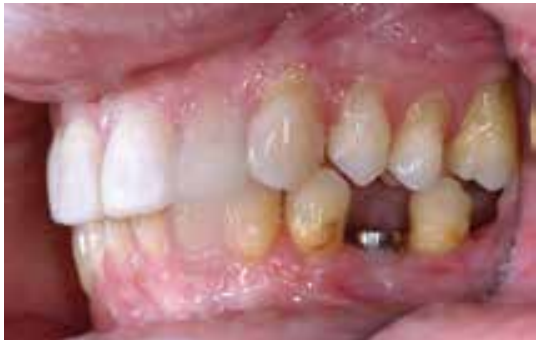

Figure 26 - Intraoral aspects after orthodontic correction and implant placement.
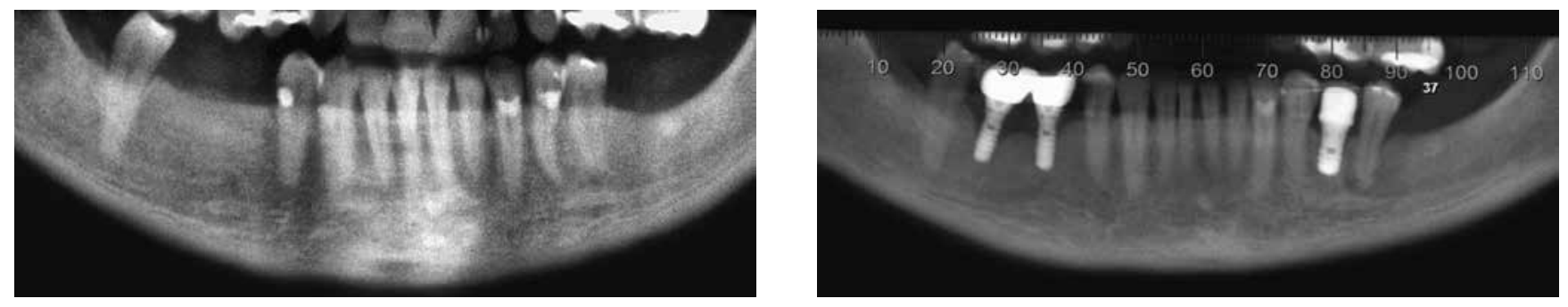

Figure 27 - Tomographic slices before and after treatment
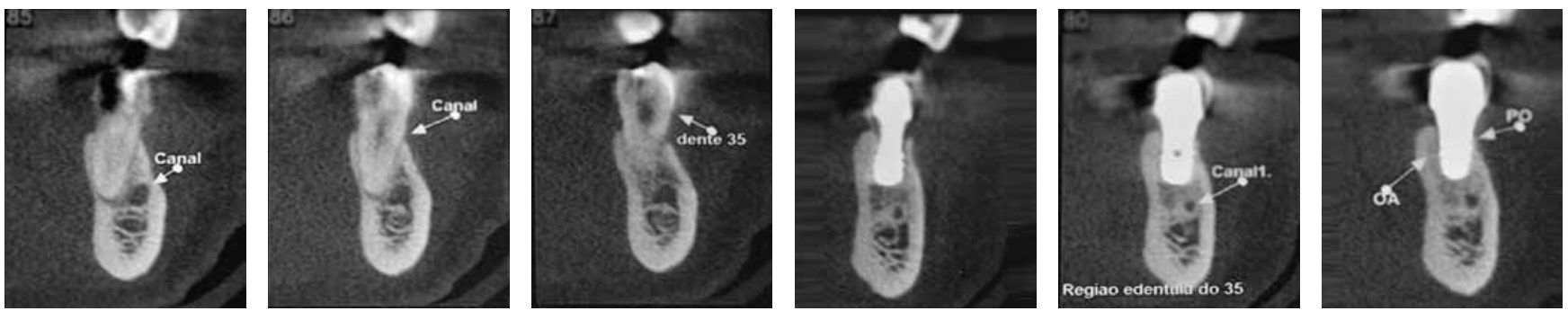

Figure 28 - Tomographic slices before (in the \#35) and after (area equivalent to \#35) implant placement. 
13. Taking into consideration the skeletal maturity at the end of adolescence, and being aware of the little orthopedic gain after this period, what is your opinion about the rapid increase of mandibular advancement appliances in adults? In which cases would these therapies be indicated and contraindicated? (Marcos Janson)

We have routinely indicated mandibular advancement appliances for growing patients (the removable ones, which depend on patient's cooperation, or the fixed ones, which are more efficient in this case). We are aware of the effects at this age: little increase in mandibular growth while the appliance has been used, upper incisor lingual inclination and lower incisors buccal inclination, distalization of upper posterior segment, increase in the anterior lower facial height (ALFH) and little clockwise inclination of the occlusal plane. For these purposes, these effects depend on the facial pattern, and it is the least indicated for dolichofacials due to the direction in which the skeletal effects occur (CoGn and ALFH). Such changes are convenient until skeletal maturity is achieved, as you have mentioned before. However, during adulthood, we can expect dental effects, only, with minimum or no skeletal results. The advancement appliances (APM, Herbst, Jasper Jump, Forsus, etc.) must not be considered as options to replace orthognathic surgery. Therefore, we first have to assess the level of skeletal discrepancy (which must be small) and preliminary compensation in Class II cases. Should there be too much lower incisor buccal inclination, the mandibular advancement appliance is contraindicated, since it will result in even greater inclination - which is non-esthetic for lower lip evertion, and dangerous for submitting the buccal bone plate to overload and occasional resorption, with gingival recession as a consequence. This danger, in particular, is worrying even for young patients. Gingival health must be continuously assessed. A thin gingival biotype and/or the absence of attached gingiva (keratinized) reveals a higher dehiscence risk and potential gingival recession in view of buccal inclination. A Cone Beam Computed Tomography may give us an idea of the amount of bone tissue that is in the buccal root surface of those teeth. In borderline cases, connective tissue graft or free gingiva graft may be indicated to protect the area before tooth movement is performed. Thus, I would say that one must be careful when using mandibular propulsion in adult patients. The skeletal anchorage (mini-implants or mini-plates) may be used to avoid side effect risks when performing tooth movement, only. Therefore, it seems reasonable to indicate the mandibular propulsion for Class II adult patients in cases in which the lower incisors are not excessively buccally inclined, there is little skeletal discrepancy, good periodontal support with a gingival thick biotype (or with graft) and a good facial pattern (meso or brachyfacial). In addition, I indicate intermaxillary anchorage for non-activated mandibular propulsion, in cases of mesialization of lower molars.

\section{As a certified member of the Brazilian Board of Orthodontics and Dentofacial Orthopedics, which are the most important criteria you think we should consider when analyzing the orth- odontic finishing of clinical cases? What advice do you give for those who intend to apply for the Brazilian Board of Orthodontics and Dentofacial Orthopedics exam? (Marcio Almeida)}

That certainly was an enhancing experience! I was encouraged by Dr. Ademir Brunetto, from Curitiba/PR, who is a great supporter of the exam and of our class as well, to apply for the BBO exam in early 2012. I am deeply thankful to Dr. Carlos Jorge Vogel and Dr. Deocleciano Carvalho for their support and endeavor, as well as to many other members of the BBO College of Diplomates (CDBBO). I have to confess that the little time I had between applying for and taking the exam (around three months) was a huge challenge. Thus, my first piece of advice is: start making plans at least one year before the exam. My second piece of advice is: take the preparatory course given by the CDBBO during the congresses held by the Brazilian Dental Association. With the course, the candidate is able to get acquainted with the analyses carried out in the exam, the criteria used to select the cases, based on the complexity degree index (IGC), ${ }^{3}$ and the criteria for case finishing evaluation, based on the grading system used by the American Board of Orthodontics ${ }^{4}$ (both articles are available in the link Extras on the website http://www.bbo.org.br). Both case difficulty criteria ${ }^{3}$ and case finishing criteria ${ }^{4}$ are a strict clinical challenge. The presented case must be considerably difficult (three cases with IGC higher than 20 and three with IGC higher than 10). 
At least one case must involve extractions and only one case involving orthognathic surgery may be included. Once the cases with the least required difficulty have been selected, they must present excellence in finishing, highlighting: accurate alignment, posterior teeth inclination (torque), intercuspation, anteroposterior relationship, overbite and overjet. All these items have a score scale based on the BBO standard ruler (used in the USA as well). Thus, the candidate is able to know how much he is going to score while presenting his cases. All of this is possible if the candidate presents flawless case records, prepared according to the $\mathrm{BBO}$ criteria (instructions are available on the website). As clinicians, we often "accept" records that, in fact, we should return to the centers to be written again. Taking this exam makes us rethink our tolerance criteria with regard to inaccurate records. I have to confess that the analysis of some case records, which I would like to take to the $\mathrm{BBO}$, made me realize that such cases did not meet the criteria because the model trimming or the photos were not adequate, among others. So, my third piece of advice is: care for and demand a perfect patient record. It also makes us rethink about those cases in which we often speed up the treatment, without caring for minor details, due to patient's demand (those who do not hesitate to ask: "When am I going to remove the appliances?"). As it has been mentioned many times by the BBO, and to which I strongly agree, "Passing the $\mathrm{BBO}$ exam does not make us better than anyone else, but it makes us better than what we were before." I strongly support this initiative which not only brings many benefits to our profession, but also adds value to it as well as to our patients.
1. Almeida MR. Ortodontia clínica e biomecânica. 1a ed. Maringá: Dental Press: 2010.

2. Arnett GW, Jelic JS, Kim J, Cummings DR, Beress A, Worley CM Jr, et al. Soft tissue cephalometric analysis: diagnosis and treatment planning of dentofacial deformity. Am J Orthod Dentofacial Orthop. 1999;116(3):239-53.

3. Cangialosi TJ, Riolo ML, Owens SE Jr, Dykhouse VJ, Moffitt AH, Grubb JE, et al. The ABO discrepancy index: a measure of case complexity. Am J Orthod Dentofacial Orthop. 2004:125(3):270-8.

4. Casko JS, Vaden JL, Kokich VG, Damone J, James RD, Cangialosi TJ, et al. Objective grading system for dental casts and panoramic radiographs. Am J Orthod Dentofacial Orthop. 1998;114(5):589-99.

5. Demito CF, Rodrigues GV, Ramos AL, Bowman SJ. Efficacy of a fluoride varnish in preventing white spot lesions as measured with laser J Clin Orthod. 2011:45(1):25-9; quiz 40.

6. Demito CF, Vivaldi-Rodrigues G, Ramos AL, Bowman SJ. The efficacy of a fluoride varnish in reducing enamel demineralization adjacent to orthodontic brackets: an in vitro study. Orthod Craniofac Res. 2004;7(4):205-10.

7. Demito CF. Efeito da nano-hidroxiapatita associada ao fluoreto na prevenção da desmineralização do esmalte adjacente aos braquetes ortodônticos: " estudo in situ" [dissertação]. Maringá (PR): Universidade Estadual de Maringá; 2013

8. Dias CS. Efficacy of a fluoride sealant and a fluoride varnish on demineralization around orthodontic brackets: in vitro study. Orthod Pract 2013:4(4). In press

9. Janson G, Branco NC, Fernandes TM, Sathler R, Garib D, Lauris JR. Influence of orthodontic treatment, midline position, buccal corridor and smile arc on smile attractiveness A systematic review. Angle Orthod. 2011;81(1):153-61.

10. Janson MRP. Ortodontia em adultos e tratamento interdisciplinar. 1a ed. Maringá: Dental Press; 2008

11. Knösel M, Eckstein A, Helms H. Durability of esthetic improvement following Icon resin infiltration of multibracket-induced white spot lesions compared with no therapy over 6 months: a single-center, split-mouth, randomized clinical trial. Am J Orthod Dentofacial Orthop. 2013;144(1):86-96.

12. Kokich VO. Perceptions of dental professionals and laypersons to altered dental esthetics: asymmetric and symmetric situations. Am J Orthod Dentofacial Orthop. 2006;130(2):141-51 
13. Matheus PD, Demito CF, Scheibel PC, Bowman SJ, Ramos AL. Correlação entre a avaliação microscópica e a leitura por laser-fluorescência de lesões de manchas brancas em dentes bovinos: estudo in vitro. Odonto (UMESP). 2010:18(36):5-13.

14. Pascotto RC, Navarro MF, Capelozza Filho L, Cury JA. In vivo effect of a resin-modified glass-ionomer cement on enamel demineralization around orthodontic brackets. Am J Orthod Dentofacial Orthop. 2004;125(1):36-41.

15. Ramos AL, Sakima MT, Santos-Pinto A, Bowman SJ. Upper lip changes correlated to maxillary incisor retraction: a metallic implant study. Angle Orthod. 2005;75(4):499-505

16. Ramos AL, Pascotto RC. Estética do sorriso. In: Associação Brasileira de Odontologia, organizador. Programa de Atualização em Ortodontia (Pro-Odonto Ortodontia). 1a ed. Porto Alegre: Artmed; Panamericana; 2007. p. 45-92
17. Rosa Jr JMP. Estudo prospectivo de movimentação dentária como alternativa para aumento do rebordo alveolar. Ortodontia (São Paulo). 2012;45:515-21.

18. Santos-Pinto A. Que recursos mecânicos o Sr. utilizaria na correção da sobremordida profunda onde a intrusão dos incisivos (superiores e/ou inferiores) é necessária? Rev Clín Ortod Dental Press. 2004;3(4):13-5.

19. Santos-Pinto A. Considerando-se que a sobremordida profunda pode também ser corrigida pela extrusão dos dentes posteriores, qual(is) a(s) mecânica(s) que o Sr. utiliza? Rev Clín Ortod Dental Press. 2004;3(6):9-16.

20. Vivaldi-Rodrigues G, Demito CF, Bowman SJ, Ramos AL. The effectiveness of a fluoride varnish in preventing the development of white spot lesions. World J Orthod. 2006:7(2):138-44.

21. Zange SE, Ramos AL, Cuoghi OA, de Mendonça MR, Suguino R. Perceptions of laypersons and orthodontists regarding the buccal corridor in long- and shortface individuals. Angle Orthod. 2011:81(1):86-90.

\section{Ary dos Santos-Pinto}

» PhD in Dentistry, Federal University of Rio de Janeiro (UFRJ).

» PostDoc in Orthodontics, Baylor College of Dentistry.

»Adjunct Professor at the Children's Clinic/Orthodontics Department at State University of São Paulo Araraquara (UNESP).

» Full professor at the Children's Clinic/Orthodontics Department at State University of São Paulo Araraquara (UNESP).

\section{Daniela Gamba Garib}

» PhD in Orthodontics and Facial Orthopedics, University of São Paulo (USP).

»Associate professor of Orthodontics at the Hospital for Rehabilitation of Craniofacial Anomalies/USP and School of Dentistry - Bauru/USP.

\section{Marcio Rodrigues Almeida}

» $\mathrm{PhD}$ in Orthodontics, School of Dentistry - Bauru/USP.

» PostDoc in Orthodontics, School of Dentistry - Bauru/ USP.

» Full professor at the Masters course in Orthodontics, University of Northern Paraná (UNOPAR).

\section{Marcos Janson}

» MSc in Dentistry, School of Dentistry - Bauru/USP.

» Coordinator of the Specialization Course in Dentistry, CIODONTO, Sertãozinho/SP. 